\title{
Performance Degradation Due to Multipath Noise for Narrowband OFDM Systems: Channel-based Analysis and Experimental Determination
}

\author{
Frederic Heereman*, Wout Joseph, Emmeric Tanghe, Leen Verloock and Luc Martens \\ Department of Information Technology, Ghent University \\ Gaston Crommenlaan 8 box 201, B-9050 Ghent, Belgium \\ Tel.: +32 9331 4908; fax: +3293314899 \\ *Email: frederic.heereman@intec.ugent.be
}

\begin{abstract}
The performance of OFDM systems over a multipath channel can strongly degrade due to the propagation delay spread. The distortion of the received signal over the FFT window, is referred to as multipath noise. This work aims to determine analytically the performance loss due to multipath noise as a function of OFDM and channel parameters for narrowband OFDM systems. First, it is investigated whether it is possible to describe the multipath noise, varying over different OFDM packets due to the temporal variation of the channel, by an effective noise factor $F_{\text {delay }}$, from which the loss factor is directly determined. Secondly, the theory of room electromagnetics is applied to develop a closed-form expression for $F_{\text {delay }}$ as a function of the OFDM and reverberation parameters. This analytical method is validated with excellent agreement. Finally, the loss factor is determined for IEEE 802.11 based on channel measurements in 2 large conference rooms, providing values up to $19 \mathrm{~dB}$ for an $800 \mathrm{~ns}$ cyclic prefix length.
\end{abstract}

Keywords: delay spread; diffuse component; room electromagnetics; reverberation time; cyclic prefix; OFDM; loss; IEEE 802.11; conference room; SIMO measurement

\section{INTRODUCTION}

OFDM (orthogonal frequency-division multiplexing) has been adopted in a wide range of wireless standards to provide a high-data-rate transmission [1]. However, the performance over a multipath channel can strongly degrade due to the propagation delay spread. This performance loss is caused by a symbol timing offset due to the distortion of the training signal [2], or also by the distortion of the received signal over the FFT (fast Fourier transform) window due to an insufficient cyclic prefix $(\mathrm{CP})$ length [3]. The latter effect will be referred to as multipath noise. Both effects can result in intersymbol interference (ISI) and intercarrier interference (ICI). Narrowband OFDM systems (e.g., IEEE $802.11 \mathrm{a} / \mathrm{g} / \mathrm{n} / \mathrm{ac}$ ), which typically have a high FFT period and a high CP length compared to the delay spread of indoor channels, are usually designed in the assumption that there is no signal distortion over the FFT window. Therefore, a simple one-tap frequency domain equalizer (FEQ) scheme without ISI/ICI cancellation (compensating for signal distortion due to the delay spread) is usually implemented in realistic narrowband OFDM receivers. However, a severe performance degradation due to the delay spread is possible in practical scenarios, as will be shown.

In literature, the interference power due to an insufficient CP length is usually analyzed based on the averaged power delay profile (APDP) under the assumption of the wide-sense stationary uncorrelated scattering (WSSUS) fading model [4]. This has been done in terms of the spectral interference power [5], [6] or the total interference power [7], [8]. In [3], [9], [10], the Doppler effect is included for time-varying channels. Another approach is presented in [11], where the interference power is based on the discrete Fourier transform (DFT) of the tail of the impulse response of a static channel. A closed-form analytical expression for the interference power as a function of OFDM and propagation parameters has been presented in [12] as an upperbound. In [13], another closed-form expression, however not derived in the paper, is used to estimate the loss factor due to an insufficient $\mathrm{CP}$ length in the case of an infinite sample rate. An analytical framework for the calculation of 
the interference due to an insufficient $\mathrm{CP}$ as well as hardware-related impairments is given in [14]. While all these references are focused on a SISO (single-input single-output) system, the interference due an insufficient CP length is studied in [15] for a network MIMO (multiple-input multiple-output) system.

Due to the temporal variation of the channel, the interference power due to an insufficient $\mathrm{CP}$ length varies over different OFDM packets. In previous studies on the APDP-based determination of the performance loss, the average of the interference power is usually taken as a performance metric. In this study, the interference is described using the concept of an effective, packetindependent additive white Gaussian noise (AWGN), from which the performance loss is directly determined.

This effective AWGN is analyzed based on the theory of room electromagnetics [16]. According to this theory, the APDP decays exponentially for a sufficiently high delay. This is a diffuse or dense channel component, i.e., composed of a non-discrete set or a non-resolvable high number of propagation paths [17]. As for narrowband OFDM indoors, a reverberation time (i.e., the decay constant of the APDP) smaller than the sampling period (i.e., typically $50 \mathrm{~ns}$ for IEEE 802.11 [18]) is realistic [19], a finite sampling rate is included in our analysis. Moreover, our analysis is not based on the assumption of the WSSUS fading model, but on the frequencyindependence of the effective AWGN.

The most important novelties of this work are summarized as follows:

(i) the description of the multipath noise by an effective AWGN: theory and validation

(ii) a closed-form analytical expression for the effective noise factor, $F_{\text {delay }}$ (including a finite sample rate)

(iii) investigation of the frequency-dependence of $F_{\text {delay }}$

(iv) the width of the spectral interference: analysis as a function of the reverberation time

(v) experimental values for $F_{\text {delay }}$ for IEEE 802.11 in large conference rooms

This paper is structured as follows. Section II presents the OFDM signal model. Our theory is provided in Section III, where the concept of the effective AWGN is derived (Section III-A) and a closed-form analytical expression for $F_{\text {delay }}$ is developed (Section III-B). The experimental validation of the theory is reported in Section IV. In Section V, the theory is applied to obtain experimental values of $F_{\text {delay }}$ for IEEE 802.11 in large conference rooms. Conclusions are drawn in Section VI.

\section{OFDM SIGNAL MODEL}

\section{A. Transmitter and channel}

The (normalized) data symbols $\tilde{X}_{m, k, i}$ to be transmitted are modulated as follows [18], [20]. Note that integer $m$ is an index referring to the OFDM packet, integer $k$ is an index referring to the OFDM symbol and integer $i$ is the subcarrier index $(i=-N,-N+1, \ldots, N$, where $N$ is a positive integer). An inverse fast Fourier transform (IFFT) is applied, after which the $\mathrm{CP}$ is inserted. We assume an idealized digital-to-analog converter (DAC), resulting into perfect analog harmonics for the different subcarriers. Finally, the signal is upconverted to the carrier frequency of the channel, $f_{c}$, and amplified.

Mathematically, the transmitted (voltage) signal for OFDM packet $m, v_{\mathrm{T}, m}(t)[\mathrm{V}]$, as a function of the time $t$ is described by:

$$
\begin{aligned}
v_{\mathrm{T}, m}(t)=g_{\mathrm{T}} \sum_{k} & \sum_{i=-N}^{N} \Re\left[\tilde{X}_{m, k, i} \exp \left(j \omega_{\mathrm{c}} t\right)\right. \\
& \times \exp \left(j i \Delta \omega_{\mathrm{subc}}\left(t-k\left(D_{\mathrm{FFT}}+D_{\mathrm{CP}}\right)\right)\right) \\
& \times\left(\mathrm{U}\left(t+D_{\mathrm{CP}}-k\left(D_{\mathrm{FFT}}+D_{\mathrm{CP}}\right)\right)\right. \\
& \left.\left.-\mathrm{U}\left(-D_{\mathrm{FFT}}-k\left(D_{\mathrm{FFT}}+D_{\mathrm{CP}}\right)\right)\right)\right],
\end{aligned}
$$

where $\Re[\cdot]$ indicates the real part of a complex number, $j$ is the imaginary unit, $\omega_{\mathrm{c}}=2 \pi f_{\mathrm{c}}, \mathrm{U}(\cdot)$ is the unit step function, $D_{\mathrm{FFT}}$ is the FFT duration, $D_{\mathrm{CP}}$ is the $\mathrm{CP}$ length, and $\Delta \omega_{\text {subc }}$ is the angular subcarrier spacing in the frequency domain: $\Delta \omega_{\mathrm{subc}}=2 \pi / D_{\mathrm{FFT}} \cdot g_{\mathrm{T}}$ [V] is a factor taking into account the amplification in the transmitter circuit and is related to the transmit power per subcarrier.

The channel is assumed to be static during one OFDM packet. For each OFDM packet $m$, the channel is described by the impulse response $c_{m}(\tau)$. The corresponding received signal is then determined by

$$
v_{\mathrm{R}, m}(t)=\int_{0}^{\infty} c_{m}(\tau) v_{\mathrm{T}, m}(t-\tau) \mathrm{d} \tau .
$$

\section{B. Receiver}

The signal processing of the receiver is schematically shown in Fig. 1 [18], [20], [21]. The received signal passes through a band-select filter and a low-noise amplifier (LNA). After down-conversion to baseband, the I/Q signals pass through a channel select-filter and a 
variable gain amplifier (VGA), which is controlled by the automatic gain control (AGC). We assume idealized filters and amplifiers (i.e., no distortion of the OFDM pulse). The resulting signal, with complex representation $v_{\mathrm{R}, \mathrm{I} / \mathrm{Q}, m}(t)$, is sampled by an analog-to-digital converter (ADC). We assume an ADC with an infinitely small resolution, an optimal FFT window positioning and no frequency synchronization algorithms. After removing the $\mathrm{CP}$ and a serial-to-parallel conversion (S/P), a fast Fourier transform (FFT) is applied. It is assumed that a one-tap frequency equalization (FEQ) and no further frequency synchronization algorithms are applied on the FFT output, $Y_{m, k, i}$. After parallel-to-serial conversion $(\mathrm{P} / \mathrm{S})$, the resulting equalized symbols, $\tilde{Y}_{m, k, i}$, are demodulated by the OFDM demapper.

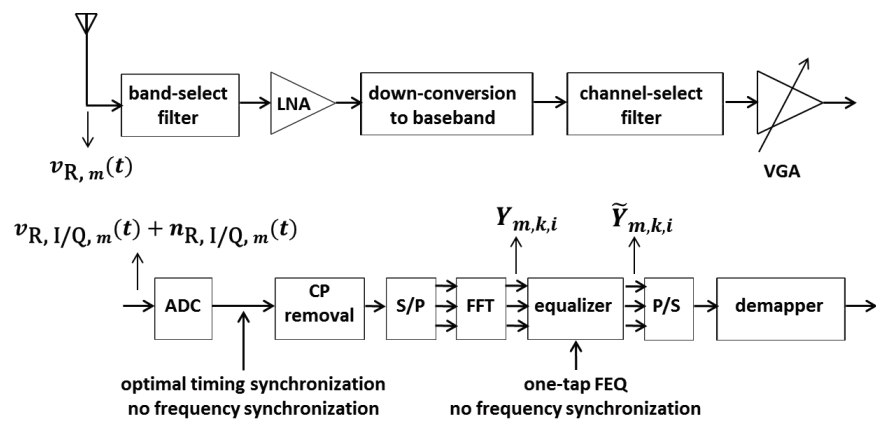

Fig. 1. Block diagram of the OFDM receiver.

A mathematical model is given as follows. $v_{\mathrm{R}, \mathrm{I} / \mathrm{Q}, m}(t)$ is obtained by amplification and down-conversion to baseband of $v_{\mathrm{R}, m}(t)$. The FFT output $Y_{m, k, i}$ is determined by the DFT of the sampled OFDM signal:

$$
\begin{gathered}
Y_{m, k, i}=\sum_{l=0}^{N_{\text {sample }}-1}\left(v_{\mathrm{R}, \mathrm{I} / \mathrm{Q}, m}\left(t_{k, l}\right)+n_{\mathrm{R}, \mathrm{I} / \mathrm{Q}, m}\left(t_{k, l}\right)\right) \\
\times \exp \left(-j 2 \pi i l / N_{\text {sample }}\right) .
\end{gathered}
$$

Here, $t_{k, l}=t_{\mathrm{win}, 0}+k\left(D_{\mathrm{FFT}}+D_{\mathrm{CP}}\right)+l D_{\mathrm{FFT}} N_{\text {sample }}^{-1}$, where $t_{\mathrm{win}, 0}$ is the optimal start instant of the FFT window for OFDM symbol $k=0 . t_{\text {win }, 0}$ will be determined in the following section. In (3), $n_{\mathrm{R}, \mathrm{I} / \mathrm{Q}, m}(t)$ is the contribution to the I/Q signal due to the AWGN (not related to the propagation channel) [22], described by a noise factor $F_{\text {AWGN }}[23]$.

$\tilde{Y}_{m, k, i}$ is obtained by dividing the FFT output by the channel estimation $H_{m, k, i}$. Taking into account that the channel estimation is based on training symbols with a large $\mathrm{CP}$ length compared to the data OFDM symbols [18], errors on $H_{m, k, i}$ due to an insufficient CP length are completely negligible. In this case, $H_{m, k, i}$ is easily determined as proportional to the channel response. Finally, the symbol error vector $\Delta \tilde{Y}_{m, k, i}$, as detected by the demapper, is determined by $\Delta \tilde{Y}_{m, k, i}=\tilde{Y}_{m, k, i}-\tilde{X}_{m, k, i}$.

\section{Optimal FFT window positioning}

The optimal FFT window positioning is determined as follows. Fig. 2 schematically shows two successive OFDM pulses (with data symbols $\tilde{X}_{0,-1, i}$ and $\tilde{X}_{0,0, i}$ ) as transmitted, $v_{\mathrm{T}, 0}(t)$, and as received, $v_{\mathrm{R}, \mathrm{I} / \mathrm{Q}, 0}(t)$.

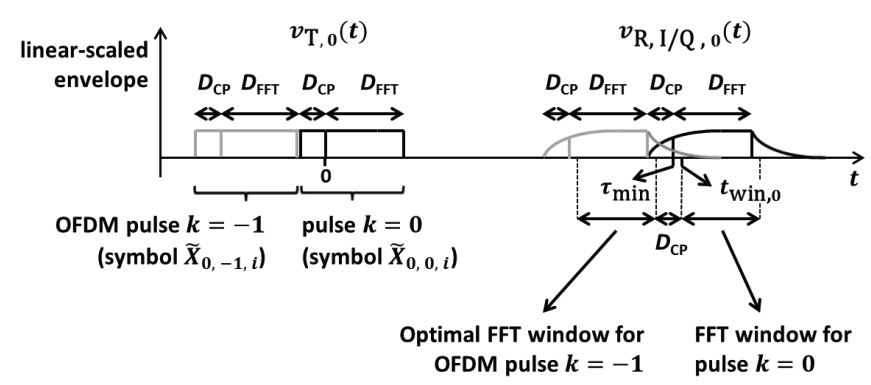

Fig. 2. Schematical (linear-scaled) envelope of 2 successive OFDM pulses with symbols $\tilde{X}_{0,-1, i}$ and $\tilde{X}_{0,0, i}$ as transmitted, $v_{\mathrm{T}, 0}(t)$, and as received, $v_{\mathrm{R}, \mathrm{I} / \mathrm{Q}, 0}(t)$. The optimal FFT window positioning considered is $t_{\mathrm{win}, 0}=\tau_{\mathrm{min}}+D_{\mathrm{FFT}} N_{\text {sample }}^{-1}$.

We assume that the optimal FFT window positioning is obtained when $t_{\mathrm{win}, 0}=\tau_{\min }+D_{\mathrm{FFT}} N_{\text {sample }}^{-1}$, where $\tau_{\min }$ is the minimum delay of the channel impulse response (i.e., the delay of the first arriving propagation path). Indeed, when $t_{\text {win }, 0}<\tau_{\min }+D_{\mathrm{FFT}} N_{\text {sample }}^{-1}$, the distortion of the (sampled) OFDM pulse $k=0$ (in the beginning of the FFT window) becomes higher compared to the optimal positioning (Fig. 2), resulting into a higher ICI. Moreover, there would be a higher ISI with the preceding OFDM pulse $(k=-1)$. On the other hand, when $t_{\text {win }, 0}>\tau_{\min }+D_{\mathrm{FFT}} N_{\text {sample }}^{-1}$, the (sampled) OFDM pulse $k=0$ would be highly distorted at the end of the FFT window, causing ICI. Moreover, the following OFDM pulse $(k=1)$ would overlap with the FFT window for OFDM symbol $k=0$, which causes severe ISI.

\section{THEORY}

A. Determination of the loss factor due to multipath noise: concept of an effective AWGN

1) Multipath noise described in terms of a packetdependent $A W G N$ : From (3), it follows that the error vector is composed of a contribution due to the AWGN, 
$\Delta \tilde{Y}_{\mathrm{AWGN}, m, k, i}$, and a contribution due to the delay spread, $\Delta \tilde{Y}_{\text {delay }, m, k, i}$ :

$$
\Delta \tilde{Y}_{m, k, i}=\Delta \tilde{Y}_{\text {AWGN }, m, k, i}+\Delta \tilde{Y}_{\text {delay }, m, k, i} .
$$

We define the instantaneous signal-to-noise ratio $\left(S N R_{\text {inst }}\right)$ as the ratio between (i) the (errorless) signal power at the demapper (of the receiver), averaged over all constellation points and (ii) the averaged error power (at the demapper) due to the thermal noise entering the receiver input:

$$
S N R_{\text {inst }}=\frac{\left\langle\left|\tilde{X}_{m, k, i}\right|^{2}\right\rangle_{k}}{\left\langle\left|\Delta \tilde{Y}_{\text {therm }, m, k, i}\right|^{2}\right\rangle_{k}} .
$$

Here, $\langle\cdot\rangle_{k}$ indicates an averaging over all OFDM symbols $k$ in a certain OFDM packet and $\Delta \tilde{Y}_{\text {therm }, m, k, i}$ is the error vector at the demapper due to the thermal noise entering the receiver input. $S N R_{\text {inst }}$ is called instantaneous because it is based on one channel realization (per OFDM packet).

To obtain a certain packet error rate (PER) (i.e., the probability that one data packet corresponding to one OFDM packet is incorrectly received after channel decoding), a certain minimum $S N R_{\text {inst }}$ is required to ensure that the signal strength is large enough compared to the symbol error vector. In the case of only symbol error $\Delta \tilde{Y}_{\mathrm{AWGN}, m, k, i}$, the minimum required $S N R_{\text {inst }}$ $\left(S N R_{\text {inst }, \text { AWGN }}\right)$ equals

$$
S N R_{\text {inst, AWGN }}=S N R_{\text {inst,therm }} F_{\text {AWGN }},
$$

where $S N R_{\text {inst,therm }}$ is the minimum required $S N R_{\text {inst }}$ in the case of only error vector $\Delta \tilde{Y}_{\text {therm }, m, k, i}$. In the case of only error vector $\Delta \tilde{Y}_{\text {delay }, m, k, i}$, the minimum required $S N R_{\text {inst }}\left(S N R_{\text {inst,delay,pack, } m}\right)$ is analogously expressed by a factor $F_{\text {delay,pack, } m \text { : }}$ :

$$
S N R_{\text {inst,delay,pack, } m}=S N R_{\text {inst,therm }} F_{\text {delay,pack }, m},
$$

where the index "pack" indicates that $S N R_{\text {inst,delay,pack, } m} \quad$ and $\quad F_{\text {delay,pack, } m} \quad$ vary over different OFDM packets due to the temporal variation of the channel. We assume that both quantities are not dependent on the subcarrier index $i$.

If $F_{\text {delay,pack, } m}$ is much larger than $F_{\text {AWGN }}$, $\Delta \tilde{Y}_{\mathrm{AWGN}, m, k, i}$ is negligible compared to $\Delta \tilde{Y}_{\text {delay }, m, k, i}$ and vice versa. Therefore, the minimum required $S N R_{\text {inst }}$ corresponding to the total error vector,
$S N R_{\text {inst,tot,pack, } m}$, is approximated by:

$$
\begin{aligned}
& S N R_{\text {inst,tot,pack, } m}= \\
& \qquad N R_{\text {inst,therm }}\left(F_{\mathrm{AWGN}}+F_{\text {delay }, \text { pack }, m}\right) .
\end{aligned}
$$

Assuming that the channel coding is done per single OFDM packet, the required PER is achieved when

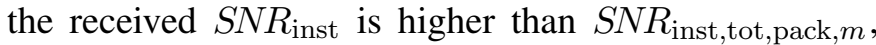
which is, from (5), equivalent to

$$
P_{\mathrm{T}, \text { subc }}\left|C_{m}\left(\omega_{i}\right)\right|^{2} \geq S N R_{\text {inst,tot,pack, } m} \frac{k_{\mathrm{B}} T}{D_{\mathrm{FFT}}},
$$

where $P_{\mathrm{T}, \mathrm{subc}}$ is the transmit power per subcarrier, $C_{m}\left(\omega_{i}\right)$ is the channel response at (angular) frequency $\omega_{i}$ of subcarrier $i$ (during the $m$ th OFDM packet), $k_{\mathrm{B}}$ is the Boltzmann constant and $T$ is the room temperature, being $290 \mathrm{~K}$ according to the IEEE Standard [23]. The outage probability $p_{\text {out }}$, i.e., the probability that the required PER is not achieved for one OFDM packet, is determined by (9).

2) Multipath noise described in terms of an effective $A W G N$ : From (8) and (9), $p_{\text {out }}$ is obtained by evaluating the $\mathrm{CDF}$ (cumulative distribution function) of $S I N R_{\text {inst }, m, i}$, defined as

$$
S I N R_{\mathrm{inst}, m, i}=\frac{D_{\mathrm{FFT}} P_{\mathrm{T}, \mathrm{subc}}}{k_{\mathrm{B}} T} \frac{\left|C_{m}\left(\omega_{i}\right)\right|^{2}}{F_{\mathrm{AWGN}}+F_{\text {delay }, \text { pack }, m}},
$$

at $S I N R_{\text {inst }, m, i}=S N R_{\text {inst,therm. In this }} \mathrm{CDF}$, the variation of $S I N R_{\text {inst }, m, i}$ is considered over all OFDM packets $m$. SINR $R_{\text {inst, } m, i}$ corresponds to the (instantaneous) signal-to-interference-plus-noise ratio (SINR) as detected at the demapper.

Further, it is assumed that $F_{\text {delay,pack, } m}$ and $\left|C_{m}\left(\omega_{i}\right)\right|^{2}$, both varying over different OFDM packets, are uncorrelated, and that $F_{\text {delay,pack, } m}$ follows roughly an exponential distribution. These assumptions allow to mathematically prove from (10) that the CDF tail (for a sufficiently low CDF level) remains unchanged when using $\left\langle F_{\text {delay,pack, } m}\right\rangle_{m}$ instead of $F_{\text {delay,pack, } m}$ in (10). Thus, for a sufficiently low $p_{\text {out }}$, the multipath noise is described by an effective AWGN with the following noise factor:

$$
F_{\text {delay }}=\left\langle F_{\text {delay,pack }, m}\right\rangle_{m} .
$$

This is an effective value, i.e., with respect to the actual reception quality (i.e., the outage probability with respect to a required PER). 
Alternatively, the actual reception quality is also described by a performance loss factor, $L_{\text {delay }}$ : the same reception quality would be obtained when the transmit power is reduced with a factor $L_{\text {delay }}^{-1}$ in the situation where no delay spread is considered. This loss can be included in link budget analysis. $L_{\text {delay }}$ is the ratio between the total noise factor, $F_{\mathrm{AWGN}}+F_{\text {delay }}$, and $F_{\text {AWGN }}$ :

$$
L_{\text {delay }}=1+\frac{F_{\text {delay }}}{F_{\text {AWGN }}} .
$$

For a realistic OFDM system, the loss factor due to the multipath noise is derived analogously. The resulting loss factor is given by (12), where $F_{\text {AWGN }}$ is replaced by $F \times L_{\text {impl. }}$. Here, $F$ and $L_{\text {impl }}$ are the conventional noise factor and the (linear-scaled) implementation loss of the realistic system, respectively. As the error vector due to multipath noise is based on an idealized OFDM system (Section II) and no additional errors are considered due to (frequency) synchronization algorithms in the realistic system, the resulting loss factor is to be considered as a lower limit for realistic OFDM systems.

\section{B. Towards a closed-form analytical expression for $F_{\text {delay }}$}

1) Analytical determination of $\Delta \tilde{Y}_{\text {delay }, m, k, i}$ : Based on the OFDM signal model (Section II), $\Delta \tilde{Y}_{\text {delay }, m, k, i^{\prime}}$ is determined in good approximation as follows:

$$
\begin{aligned}
& \Delta \tilde{Y}_{\text {delay }, m, k, i^{\prime}}= \\
& \frac{1}{C_{m}\left(\omega_{i^{\prime}}\right)} \sum_{i=-N}^{N} \frac{-\tilde{X}_{m, k, i}+\tilde{X}_{m, k-1, i} \exp \left(j i \Delta \omega_{\text {subc }} D_{\mathrm{CP}}\right)}{\exp \left(j\left(i^{\prime}-i\right) \Delta \omega_{\text {subc }}\left(\tau_{\min }+D_{\mathrm{FFT}} N_{\text {sample }}^{-1}\right)\right)} \\
& \quad \times\left(y_{\text {corr }, m}\left(\omega_{i}\right)+y_{\mathrm{Four}, m}\left(\omega_{i}, i^{\prime}-i\right)\right) .
\end{aligned}
$$

Here, $\omega_{i}$ and $\omega_{i^{\prime}}$ are the (angular) frequency of subcarrier $i$ and $i^{\prime}$, resp.: $\omega_{i}=\omega_{\mathrm{c}}+i \Delta \omega_{\text {subc }}$ and $\omega_{i^{\prime}}=\omega_{\mathrm{c}}+i^{\prime} \Delta \omega_{\mathrm{subc}}$. This approximation holds (with a deviation of the (average) power less than $0.5 \mathrm{~dB}$ ) for $\tau_{\mathrm{r}}<0.2 D_{\mathrm{FFT}}$, where $\tau_{r}$ is the reverberation time. This is realistic for narrowband OFDM systems (such as IEEE 802.11) in an indoor environment. In interference coefficient $y_{\text {Four }, m}\left(\omega_{i}, i^{\prime}-i\right)$, the index "Four" refers to the fact that these coefficients are related to the decomposition of the received signal over the FFT window into a Fourier series. This contribution to the error vector corresponds to the case of an infinite sample rate. In interference coefficient $y_{\text {corr }, m}\left(\omega_{i}\right)$, the index "corr" indicates that this is a correction term due to the finite sample rate.
The terms in (13) proportional to $\tilde{X}_{m, k-1, i}$ (for $-N \leq i \leq N)$ are due to ISI, while the terms proportional to $\tilde{X}_{m, k, i}$ for which $i \neq i^{\prime}$ are due to ICI. The term proportional to $\tilde{X}_{m, k, i^{\prime}}$ is due to the fact that the channel equalization coefficient, $H_{m, k, i^{\prime}}$, does not compensate for the distortion of the received signal over the FFT integration interval. ISI with other preceding OFDM symbols ( $k-2$ and lower) is negligible (with a deviation of the (average) power less than $0.5 \mathrm{~dB}$ ) when $\tau_{\mathrm{r}}$ is lower than $0.4\left(D_{\mathrm{FFT}}+D_{\mathrm{CP}}\right)$. The interference coefficients $y_{\mathrm{corr}, m}(\omega)$ and $y_{\mathrm{Four}, m}\left(\omega, i^{\prime}-i\right)$ are determined analytically based on the channel impulse response using weighting functions $f_{\text {corr }}(\tau)$ and $f_{\mathrm{Four}, i^{\prime}-i}(\tau)$, resp. (Appendix A).

2) Determination of $F_{\text {delay }}$ based on $\left\langle\left|y_{\text {corr }, m}(\omega)\right|^{2}\right\rangle_{m, \omega}$ and $\left\langle\left|y_{\text {Four }, m}\left(\omega, i^{\prime}-i\right)\right|^{2}\right\rangle_{m, \omega}$ :

Assuming that $\Delta \tilde{Y}_{\text {delay }, m, k, i}$, varying over different OFDM symbols $k$, behaves as a complex Gaussian variable, $F_{\text {delay,pack, } m}$ is simply determined by

$$
F_{\text {delay }, \text { pack }, m}=\frac{\left\langle\left|\Delta \tilde{Y}_{\text {delay }, m, k, i}\right|^{2}\right\rangle_{k}}{\left\langle\left|\Delta \tilde{Y}_{\text {therm }, m, k, i}\right|^{2}\right\rangle_{k}} .
$$

From (11), (13) and (14), it follows that the effective noise factor at subcarrier $i^{\prime}$ is given by

$$
\begin{aligned}
F_{\text {delay }} & =\frac{2 D_{\mathrm{FFT}} P_{\mathrm{T}, \mathrm{subc}}}{k_{\mathrm{B}} T} \\
& \times \sum_{i=-N}^{N}\left\langle\left|y_{\mathrm{corr}, m}\left(\omega_{i}\right)+y_{\mathrm{Four}, m}\left(\omega_{i}, i^{\prime}-i\right)\right|^{2}\right\rangle_{m} .
\end{aligned}
$$

Here, it is assumed that the data symbols $\tilde{X}_{m, k, i}$ are uncorrelated.

In (15), $\left\langle\left|y_{\text {corr }, m}(\omega)+y_{\text {Four }, m}\left(\omega, i^{\prime}-i\right)\right|^{2}\right\rangle_{m}$ is estimated by $\left\langle\left|y_{\text {corr }, m}(\omega)\right|^{2}\right\rangle_{m}+\left\langle\left|y_{\text {Four }, m}\left(\omega, i^{\prime}-i\right)\right|^{2}\right\rangle_{m}$. Assuming that these 2 interference power terms are constant over the considered frequency band $f_{\text {band, }, 1}<$ $\omega /(2 \pi)<f_{\text {band, } 2}$, it follows from (15) that $F_{\text {delay }}$ is approximately given by

$$
\begin{aligned}
F_{\text {delay }} & =\frac{2 D_{\mathrm{FFT}} P_{\mathrm{T}, \mathrm{subc}}}{k_{\mathrm{B}} T}\left((2 N+1)\left\langle\left|y_{\mathrm{corr}, m}(\omega)\right|^{2}\right\rangle_{m, \omega}\right. \\
& \left.+\sum_{i=-N}^{N}\left\langle\left|y_{\mathrm{Four}, m}\left(\omega, i^{\prime}-i\right)\right|^{2}\right\rangle_{m, \omega}\right)
\end{aligned}
$$

where $\langle\cdot\rangle_{m, \omega}$ indicates an averaging over the different OFDM packets $m$ and over the aforementioned frequency band. 
3) Analytical expression for $\left\langle\left|y_{\mathrm{corr}, m}(\omega)\right|^{2}\right\rangle_{m, \omega}$ and $\left\langle\left|y_{\text {Four }, m}\left(\omega, i^{\prime}-i\right)\right|^{2}\right\rangle_{m, \omega}$ : From (23a) (Appendix A) and Parseval's theorem, $\left\langle\left|y_{\text {corr }, m}(\omega)\right|^{2}\right\rangle_{m, \omega}$ is calculated in good approximation as:

$$
\begin{aligned}
& \left\langle\left|y_{\text {corr }, m}(\omega)\right|^{2}\right\rangle_{m, \omega}= \\
& \frac{8}{3} \sum_{l=0}^{N_{0}-1}\left|f_{\text {corr }}\left(\tau_{l}-\tau_{0}\right)\right|^{2}\left|c_{\text {APDP }}(l)\right|^{2},
\end{aligned}
$$

where $\tau_{l}=\Delta f_{\text {win,mov }}^{-1} l, \tau_{0}=\tau_{\text {min }}+D_{\mathrm{CP}}+D_{\mathrm{FFT}}+$ $D_{\text {FFT }} N_{\text {sample }}^{-1}$ and $\left|c_{\text {APDP }}(l)\right|^{2}$ are the coefficients of the APDP, i.e., $\left|c_{\operatorname{APDP}}(l)\right|^{2}=\left\langle\left|c_{m, f_{\text {win,mov }}}(l)\right|^{2}\right\rangle_{m, f_{\text {win,mov }}}$. Here, the coefficients $c_{m, f_{\text {win,mov }}}(l)\left(l=0, \ldots, N_{0}-1\right)$ are the inverse discrete Fourier transform (IDFT) of the sampled channel response, after applying a Hann window with center frequency $f_{\text {win,mov }}$. $N_{0}$ is the number of the channel response samples over the window width, $\Delta f_{\text {win,mov }}$. The average $\langle\cdot\rangle_{m, f_{\text {win,mov }}}$ is over all OFDM packets $m$ and over the considered frequency band, $f_{\text {band, } 1}<f_{\text {win,mov }}<f_{\text {band,2 }}$. Analogously, $\left\langle\left|y_{\text {Four }, m}\left(\omega, i^{\prime}-i\right)\right|^{2}\right\rangle_{m, \omega}$ is determined from (23b) as

$$
\begin{aligned}
\left\langle\left|y_{\text {Four }, m}\left(\omega, i^{\prime}-i\right)\right|^{2}\right\rangle_{m, \omega}= & \\
& \frac{8}{3} \sum_{l=0}^{N_{0}-1}\left|f_{\mathrm{Four}, i^{\prime}-i}\left(\tau_{l}-\tau_{0}\right)\right|^{2}\left|c_{\mathrm{APDP}}(l)\right|^{2} .
\end{aligned}
$$

According to the theory of room electromagnetics [16] for indoor environments, the tail of the APDP is described by an exponential decay:

$$
\left|c_{\mathrm{APDP}}(l)\right|^{2}=\left|c_{\mathrm{RE}}\right|^{2} \exp \left(-\frac{\tau_{l}-\tau_{\min }}{\tau_{\mathrm{r}}}\right),
$$

where $\left|c_{\mathrm{RE}}\right|^{2}$ is a proportionality factor. We assume that this applies for the relevant part of the channel impulse response, i.e., where $f_{\text {corr }}\left(\tau_{l}-\tau_{0}\right)$ and $f_{\mathrm{Four}, i^{\prime}-i}\left(\tau_{l}-\tau_{0}\right)$ are non-zero. From (17), (18), (19) and Appendix A, $\left\langle\left|y_{\text {corr }, m}(\omega)\right|^{2}\right\rangle_{m, \omega}$ and $\left\langle\left|y_{\text {Four }, m}\left(\omega, i^{\prime}-i\right)\right|^{2}\right\rangle_{m, \omega}$ are determined as a closedform analytical expression as a function of OFDM parameters, $\left|c_{\mathrm{RE}}\right|^{2}$ and $\tau_{\mathrm{r}}$. In particular, we obtain in good approximation:

$$
\begin{aligned}
& \left\langle\left|y_{\text {corr }, m}(\omega)\right|^{2}\right\rangle_{m, \omega} \approx \\
& \frac{1}{3 \pi N_{\text {sample }}^{2}} I_{\text {diff }} \tau_{\mathrm{r}} \exp \left(-\frac{D_{\mathrm{CP}}+D_{\mathrm{FFT}} N_{\text {sample }}^{-1}}{\tau_{\mathrm{r}}}\right) \\
& \left\langle\left|y_{\mathrm{Four}, m}\left(\omega, i^{\prime}-i=0\right)\right|^{2}\right\rangle_{m, \omega} \approx \\
& \frac{8}{3 \pi} I_{\mathrm{diff}} \frac{\tau_{\mathrm{r}}^{3}}{D_{\mathrm{FFT}}^{2}} \exp \left(-\frac{D_{\mathrm{CP}}+D_{\mathrm{FFT}} N_{\text {sample }}^{-1}}{\tau_{\mathrm{r}}}\right) .
\end{aligned}
$$

This approximation holds with a deviation of the averaged power lower than $0.5 \mathrm{~dB}$ for $\tau_{\mathrm{r}}<0.2 D_{\mathrm{FFT}}$. In (20a)-(20b), $\left|c_{\mathrm{RE}}\right|^{2}$ is expressed by $I_{\text {diff }}[\mathrm{Hz}]=$ $\left|c_{\mathrm{RE}}\right|^{2} \Delta f_{\text {win,mov }}$, which is not dependent on the window width $\Delta f_{\text {win,mov }}$. Indeed, as the time resolution of the APDP is the inverse of $\Delta f_{\text {win,mov }},\left|c_{\mathrm{RE}}\right|^{2}$ is inversely proportional to $\Delta f_{\text {win,mov }}$.

4) Spectral interference profile: Analytical expressions for $\left\langle\left|y_{\text {Four, } m}\left(\omega, i^{\prime}-i\right)\right|^{2}\right\rangle_{m, \omega}$ based on (18) and (19) are much more complicated for $\left|i^{\prime}-i\right| \geq 1$ than for $i^{\prime}=i$, see (20b). To derive a simplified closed-form expression from (16) for $F_{\text {delay, }}$, the spectral profile of $\left\langle\left|y_{\text {Four }, m}\left(\omega, i^{\prime}-i\right)\right|^{2}\right\rangle_{m, \omega}$ is analyzed. "Spectral" indicates that the interference power due to a single transmitting subcarrier is evaluated as a function of the subcarrier where the interference is detected. We find that the ratio between $\left\langle\left|y_{\text {Four }, m}\left(\omega, i^{\prime}-i\right)\right|^{2}\right\rangle_{m, \omega}$ and $\quad\left\langle\left|y_{\text {Four }, m}(\omega, 0)\right|^{2}\right\rangle_{m, \omega} \quad$ is approximately $\left(\left|i^{\prime}-i\right| \Delta \omega_{\text {subc }} \tau_{\mathrm{r}}\right)^{-2}$ (with a deviation smaller than $1 \mathrm{~dB})$ for $\left|i^{\prime}-i\right| \Delta \omega_{\mathrm{subc}} \tau_{\mathrm{r}}>2$. Consequently, the frequency width of the spectral interference power $\left\langle\left|y_{\text {Four }, m}\left(\omega, i^{\prime}-i\right)\right|^{2}\right\rangle_{m, \omega}$ is $1 /\left(2 \tau_{\mathrm{r}}\right)$ and the number of interfering subcarriers equals $D_{\mathrm{FFT}} /\left(2 \tau_{\mathrm{r}}\right)$ (after rounding up).

5) Closed-form analytical expression for $F_{\text {delay: }}$ : Based on Section III-B4, the second term in (16) is estimated as composed of $\min \left(2 N+1, D_{\mathrm{FFT}} /\left(2 \tau_{\mathrm{r}}\right)\right)$ equal terms, where $\min (\cdot, \cdot)$ is the minimum of the arguments. Consequently, using (20a) and (20b), (16) is written as

$$
\begin{aligned}
F_{\text {delay }} & =\frac{4}{3} \frac{D_{\mathrm{FFT}} P_{\mathrm{T}, \text { subc }}}{k_{\mathrm{B}} T} I_{\mathrm{diff}} \tau_{\mathrm{r}} \\
& \times \exp \left(-\frac{D_{\mathrm{CP}}+D_{\mathrm{FFT}} N_{\text {sample }}^{-1}}{\tau_{\mathrm{r}}}\right) \\
& \times\left(\frac{N_{\text {subc }}}{N_{\text {sample }}^{2}}+8 \min \left(N_{\mathrm{subc}}, \frac{D_{\mathrm{FFT}}}{2 \tau_{\mathrm{r}}}\right)\left(\frac{\tau_{\mathrm{r}}}{D_{\mathrm{FFT}}}\right)^{2}\right),
\end{aligned}
$$

where $N_{\text {subc }}$ represents the number of subcarriers used for transmission: $N_{\text {subc }}=2 N+1$. The finite sample rate has the following effects on $F_{\text {delay }}$ : (i) the sampling period $D_{\mathrm{FFT}} / N_{\text {sample }}$ acts as an extension of the CP length and (ii) an additional interference term (i.e., the first term in (21)). For IEEE 802.11a, this term becomes dominant for $\tau_{\mathrm{r}}<17 \mathrm{~ns}$. 


\section{EXPERIMENTAL VALIDATION}

\section{A. Measurements and data processing}

Measurements were executed in 2 large conference rooms with a virtual single-input multiple-output (SIMO) system. In this setup, the Tx and Rx antenna, both broadband omnidirectional Electro-Metrics antennas of type EM-6116, were connected to a Rohde \& Schwarz ZVR vector network analyzer, which measured the scattering parameter $S_{21}$ as a function of the frequency. A coaxial cable with two amplifiers was used to realize the $\mathrm{Tx}^{\mathrm{x}}$ $\mathrm{Rx}$ separation. The Rx antenna was attached to a twodimensional positioning system.

The measurements were done in the frequency range $2.5-3 \mathrm{GHz} .801$ frequency points were used, which allows to resolve power delay profiles for delays up to $1.6 \mu$ s (larger than an $800 \mathrm{~ns}$ CP [18]). A $23 \times 23 \mathrm{Rx}$ array was used, with a separation of $1.5 \mathrm{~cm}$.

In room A, repeated reception problems were reported with an IEEE 802.11a audio conference system. This system has a SISO configuration without antenna diversity. According to the manufacturer, these problems occur specifically in this conference room and cannot be attributed to interference sources after spectral analysis.

The following positions of $\mathrm{Tx}$ and the $\mathrm{Rx}$ array were chosen in room A (Fig. 3): Tx at position 1 (usual position of the access point during meetings) and $\mathrm{Rx}$ at position 2 (case 1a) (and vice versa (case 1b)), and Tx at position 1 and $\mathrm{Rx}$ at position 3 (case $2 \mathrm{a}$ ) (and vice versa (case $2 b)$ ). At position 1, the height of the antenna (Tx or $\mathrm{Rx}$ ) was always $1.8 \mathrm{~m}$, while at positions 2 and 3, the antenna height was always $1.2 \mathrm{~m}$. The Tx-Rx separation was $8.9 \mathrm{~m}$ for case $1 \mathrm{a}-\mathrm{b}$ and $6.9 \mathrm{~m}$ for case $2 \mathrm{a}-\mathrm{b}$.

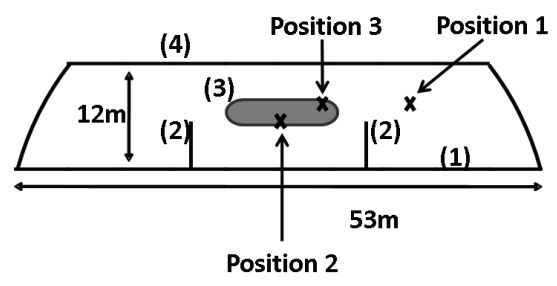

Fig. 3. Floor plan of room A. The conference table is indicated by (3). Measurements were executed at Tx/Rx positions $1-3$.

The wall behind position 2 (indicated as (1) in Fig. 3) and the two dividing walls ((2) in Fig. 3) contain about 30 metal HVAC (Heating, Ventilation, and Air Conditioning) plates (with dimensions $1 \mathrm{~m}$ by $1.5 \mathrm{~m}$ ). The wall at the other side ((4) in Fig. 3) consists of windows only. The ceiling, which looks like a part of an ellipsoid, contains a metal wire mesh, with a separation of about $1 \mathrm{~cm}$. The dimensions of the room are $12 \mathrm{~m} \times$ $53 \mathrm{~m}$ and the ceiling has a maximal height of $13 \mathrm{~m}$.

For comparison, measurements were also executed in conference room B. The dimensions are $10 \mathrm{~m} \times 32 \mathrm{~m}$ and the ceiling, which is approximately a horizontal plane, has a height of about $6 \mathrm{~m}$. Tx is positioned around the conference table (in the middle of the room) as an access point at a height of $2.1 \mathrm{~m}$. The $\mathrm{Rx}$ array is set at 2 positions (case $3 \mathrm{a}$ and $3 \mathrm{~b}$, resp.) at the conference table at a height of $1.5 \mathrm{~m}$. Only one wall contains windows ( 8 windows with dimensions $2 \mathrm{~m} \times 3 \mathrm{~m}$ ). The Tx-Rx separation was $9.7 \mathrm{~m}$ and $8.3 \mathrm{~m}$ for case $3 \mathrm{a}$ and $3 \mathrm{~b}$, respectively. For all measurements (rooms A and B), there was a line-of-sight condition.

For the data processing, the interference coefficients $y_{\text {corr }, m}(\omega)$ and $y_{\text {Four }, m}\left(\omega, i^{\prime}-i\right)$ (Appendix A) are written in terms of a (baseband) tapped delay line channel model, with impulse response:

$$
\begin{aligned}
& c_{\text {baseband }, m, f_{\text {win,mov }}}(\tau)= \\
& \sum_{l=0}^{N_{0}-1} c_{m, f_{\text {win,mov }}}(l) \delta\left(\tau-\Delta f_{\text {win,mov }}^{-1} l\right),
\end{aligned}
$$

where $\delta(\cdot)$ denotes the Dirac delta function. The coefficients $c_{m, f_{\text {win,mov }}}(l)$ are obtained as the IDFT of the channel response measured over a frequency width $\Delta f_{\text {win,mov }}$, after multiplying by a Hann window with center frequency $f_{\text {win,mov }}$ [24]. $N_{0}$ is the number of the measured channel response samples in this frequency width $\Delta f_{\text {win,mov }}$. To calculate $y_{\text {corr, } m}(\omega)$ and $y_{\text {Four, } m}\left(\omega, i^{\prime}-i\right)$ over the frequency band $2.65 \mathrm{GHz}<$ $\omega /(2 \pi)<2.85 \mathrm{GHz}$, a moving Hann window is applied with a center frequency $f_{\text {win,mov }}$ varying from $2.65 \mathrm{GHz}$ to $2.85 \mathrm{GHz}$ and with a window width of $\Delta f_{\text {win,mov }}=$ $300 \mathrm{MHz}$.

\section{B. Validation with respect to the concept of an effective $A W G N$}

In this section, the description of the multipath noise by an effective AWGN, which has been theoretically shown for a sufficiently low outage probability $p_{\text {out }}$ (Section III-A), is validated experimentally for realistic values of $p_{\text {out }}$. For this validation, $S I N R_{\text {inst }, m, i}$ (defined by (10)) is considered as a performance metric. First, $S I N R_{\text {inst }, m, i}$ is determined exactly (based on (13) and (14), assuming uncorrelated data symbols). Secondly, 
$S I N R_{\text {inst }, m, i}$ is determined based on the effective noise factor, $\left\langle F_{\text {delay,pack, } m}\right\rangle_{m}$, used instead of $F_{\text {delay,pack, } m}$ in (10). In this validation, we focus on the interference detected at subcarrier $i^{\prime}=0$. Typical IEEE 802.11 OFDM parameters are used: a total transmit power $P_{\mathrm{T}}=20 \mathrm{dBm}, F_{\mathrm{AWGN}}=15 \mathrm{~dB}, D_{\mathrm{FFT}}=3.2 \mu \mathrm{s}$ and a $20 \mathrm{MHz}$ channel bandwidth.

The variation of $F_{\text {delay,pack, } m}$ over different OFDM packets (due to the temporal variation of the channel) is considered by the variation over the spatial smallscale Rx position. In both cases, $F_{\text {delay,pack, } m}$ is based on a high number of diverse propagation paths arriving after several reflections or diffractions in the room and interfering in a varying way. Moreover, it is assumed that the $F_{\text {delay,pack, } m}$ sample set is statistically independent on the carrier frequency in the range $2.65-2.85 \mathrm{GHz}$. Hence, the validation is done using an $F_{\text {delay,pack, } m}$ sample set including a variation over all OFDM packets $m$ as well as over the frequency band $2.65-2.85 \mathrm{GHz}$.

For all cases in room A and $D_{\mathrm{CP}}=400 / 800 \mathrm{~ns}$, the CDF of $S I N R_{\text {inst }, m, i}$ is calculated exactly, as well as based on the effective noise factor. We find that the maximum power deviation for a CDF level $p_{\text {out }}<20 \%$ is maximum $0.6 \mathrm{~dB}$ and $1 \mathrm{~dB}$ for $p_{\text {out }}<50 \%$. This is illustrated for case $1 \mathrm{~b}$ and $D_{\mathrm{CP}}=800 \mathrm{~ns}((1)$ and (2) in Fig. 4). This shows that the concept of the effective AWGN is applicable for realistic values of $p_{\text {out }}$ (i.e., $<50 \%$ ): the packet-dependent multipath noise is described by an effective (packet-independent) AWGN, with noise factor $F_{\text {delay }}=\left\langle F_{\text {delay,pack, } m}\right\rangle_{m}$.

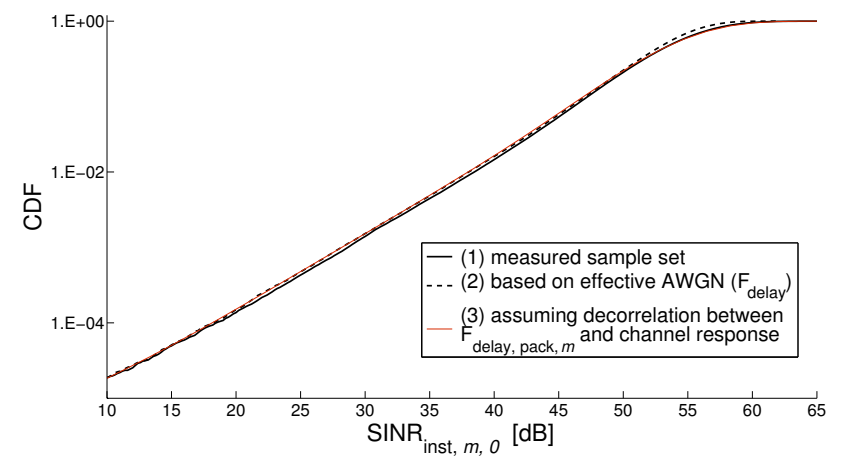

Fig. 4. Based on a virtual SIMO measurement, the CDF of $S I N R_{\text {inst }, m, 0}$ (curve (1)) is calculated for $D_{\mathrm{CP}}=800 \mathrm{~ns}$. For $p_{\text {out }}<50 \%$, an excellent agreement is found with the CDF based on the effective noise factor $F_{\text {delay }}$ (curve (2)). CDF (3) is calculated assuming a decorrelation between $F_{\text {delay,pack, } m}$ and the channel response.

In the theoretical derivation of the effective AWGN
(Section III-A), it has been assumed that $F_{\text {delay,pack, } m}$ and $\left|C_{m}\left(\omega_{i}\right)\right|^{2}$ are uncorrelated. For all cases in room A and $D_{\mathrm{CP}}=400 / 800 \mathrm{~ns}$, we find that the maximum power deviation between the measured $\mathrm{CDF}$ and the CDF assuming a perfect decorrelation ((3) in Fig. 4) is smaller than $0.9 \mathrm{~dB}$ for $p_{\text {out }}<50 \%$. Indeed, $F_{\text {delay,pack, } m}$ is based on the diffuse component of the channel. This component consists of a high number of propagation paths with several reflections or diffractions, while the channel response is mainly determined by the first arriving few paths. A second assumption made in Section III-A2 is that $F_{\text {delay,pack, } m}$ follows roughly an exponential distribution, which is also validated experimentally for room A. This is shown in Fig. 5 for case $1 \mathrm{~b}$ and $D_{\mathrm{CP}}=800 \mathrm{~ns}$.

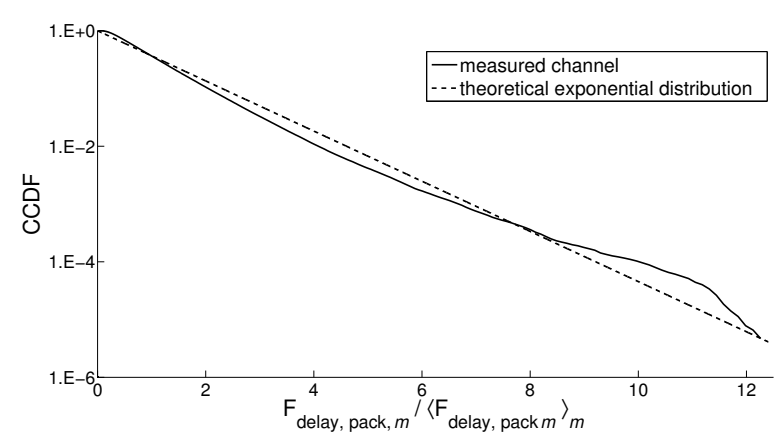

Fig. 5. The complementary CDF (CCDF) of the ratio between $F_{\text {delay,pack, } m}$ and its average (solid line) is determined for $D_{\mathrm{CP}}=$ 800 ns. This is compared with the theoretical CCDF (dashed line) assuming $F_{\text {delay,pack, } m}$ as an exponentially distributed variable.

C. Validation of the frequency-independence of $\left\langle\left|y_{\text {corr }, m}(\omega)\right|^{2}\right\rangle_{m}$ and $\left\langle\left|y_{\text {Four }, m}\left(\omega, i^{\prime}-i\right)\right|^{2}\right\rangle_{m}$

In Section III-B2, we assumed that $\left\langle\left|y_{\text {corr, } m}(\omega)\right|^{2}\right\rangle_{m}$ and $\left\langle\left|y_{\text {Four }, m}\left(\omega, i^{\prime}-i\right)\right|^{2}\right\rangle_{m}$ are frequency-independent. In Fig. 6, these interference powers are shown as a function of the frequency for case $1 \mathrm{~b}$ (room A), $D_{\mathrm{CP}}=$ $800 \mathrm{~ns}$ and subcarrier separation $\left|i^{\prime}-i\right|=0,5,10$ and 15. Very similar results are obtained for the other cases for room $\mathrm{A}$ and $D_{\mathrm{CP}}=400 / 800 \mathrm{~ns}$. The maximum variation of the interference power terms over a channel bandwidth of $20 \mathrm{MHz}$ is about $\pm 2 \mathrm{~dB}$. The terms decrease slightly over the considered frequency range with less than $3 \mathrm{~dB}$. We conclude that $\left\langle\left|y_{\text {corr }, m}(\omega)\right|^{2}\right\rangle_{m}$ and $\left\langle\left|y_{\text {Four }, m}\left(\omega, i^{\prime}-i\right)\right|^{2}\right\rangle_{m}$ can be considered as frequencyindependent, in order to derive (16) (Section III-B2). 


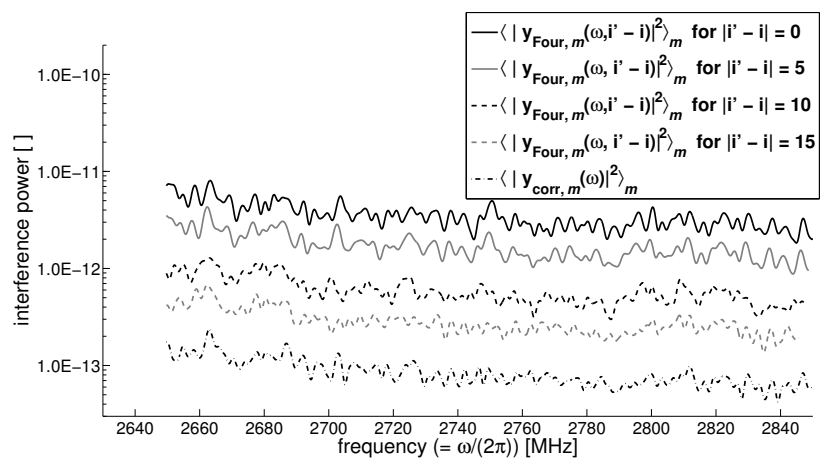

Fig. 6. $\left\langle\left|y_{\text {corr }, m}(\omega)\right|^{2}\right\rangle_{m}$ and $\left\langle\left|y_{\text {Four }, m}\left(\omega, i^{\prime}-i\right)\right|^{2}\right\rangle_{m}$ are experimentally determined for $\left|i^{\prime}-i\right|=0,5,10$ and 15 . Only a small variation over the considered frequency band is found.

D. Validation of the APDP-based and analytical method for the determination of $\left\langle\left|y_{\mathrm{corr}, m}(\omega)\right|^{2}\right\rangle_{m, \omega}$ and $\left\langle\left|y_{\text {Four }, m}\left(\omega, i^{\prime}-i\right)\right|^{2}\right\rangle_{m, \omega}$

Most rigorously, the interference power terms $\left\langle\left|y_{\text {corr }, m}(\omega)\right|^{2}\right\rangle_{m, \omega}$ and $\left\langle\left|y_{\text {Four }, m}\left(\omega, i^{\prime}-i\right)\right|^{2}\right\rangle_{m, \omega}$ are determined from the measured samples $y_{\mathrm{corr}, m}(\omega)$ and $y_{\text {Four, } m}\left(\omega, i^{\prime}-i\right)$ (samples-based method). The 2 proposed simplified methods (Section III-B3) are resp. based on (i) the measured APDP and a weighting function ((17)-(18), APDP-based method) and (ii) the theory of room electromagnetics (analytical method). The analytical method is based on (17)-(19), where $\tau_{\mathrm{r}}$ and $I_{\text {diff }}$ are to be determined from the APDP.

For the validation of the analytical method, $\tau_{\mathrm{r}}$ and $I_{\text {diff }}$ are determined from the virtual SIMO measurements in rooms A and B (Table I). These parameters are determined using linear regression of the APDP in log-lin scale. For room A, the fitting according to (19) is based on the delay interval with start $\tau_{\text {min }}+$ $D_{\mathrm{CP}}+D_{\mathrm{FFT}} N_{\text {sample }}^{-1}$ and with a duration of 4 times $\tau_{\mathrm{r}}$. For room B, the fitting is based on the delay interval $[200,400] \mathrm{ns}$, because the APDP cannot be detected for higher delays due to the measurement noise level. In room $\mathrm{A}, \tau_{\mathrm{r}}$ varies from $109 \mathrm{~ns}$ to $116 \mathrm{~ns}$ for $D_{\mathrm{CP}}=$ $400 \mathrm{~ns}$ and from $129 \mathrm{~ns}$ to $137 \mathrm{~ns}$ for $D_{\mathrm{CP}}=800 \mathrm{~ns}$. This is strikingly higher than in room $\mathrm{B}$, where $\tau_{\mathrm{r}}=$ $35-36 \mathrm{~ns}$. In room A, we find that $I_{\text {diff }}=6-12 \mathrm{~Hz}$ and $3-4 \mathrm{~Hz}$ for $D_{\mathrm{CP}}=400 \mathrm{~ns}$ and $800 \mathrm{~ns}$, resp., and $12-21 \mathrm{~Hz}$ in room $\mathrm{B}$.

$\left\langle\left|y_{\text {corr }, m}(\omega)\right|^{2}\right\rangle_{m, \omega}$ and $\left\langle\left|y_{\text {Four }, m}\left(\omega, i^{\prime}-i\right)\right|^{2}\right\rangle_{m, \omega}$ are calculated for $0 \leq\left|i^{\prime}-i\right| \leq 19$ based on the (i) samplesbased, (ii) APDP-based and (iii) analytical method. For the interference term with index "Four", this is shown in
TABLE I

MEASURED REVERBERATION PARAMETERS: $\tau_{\mathrm{r}}$ AND $I_{\text {diff }}$

\begin{tabular}{|c|c|c|c|c|}
\hline & & $D_{\mathrm{CP}}[\mathrm{ns}]$ & $\tau_{\mathrm{r}}[\mathrm{ns}]$ & $I_{\text {diff }}[\mathrm{Hz}]$ \\
\hline \multirow[t]{8}{*}{ room $\mathrm{A}$} & \multirow{2}{*}{ case $1 \mathrm{a}$} & 400 & $110 \pm 3$ & $9 \pm 3$ \\
\hline & & 800 & $134 \pm 4$ & $3 \pm 1$ \\
\hline & \multirow[t]{2}{*}{ case $1 \mathrm{~b}$} & 400 & $113 \pm 4$ & $6 \pm 2$ \\
\hline & & 800 & $131 \pm 4$ & $3 \pm 1$ \\
\hline & \multirow[t]{2}{*}{ case $2 a$} & 400 & $109 \pm 3$ & $12 \pm 4$ \\
\hline & & 800 & $137 \pm 4$ & $3 \pm 1$ \\
\hline & \multirow[t]{2}{*}{ case $2 b$} & 400 & $116 \pm 4$ & $9 \pm 3$ \\
\hline & & 800 & $129 \pm 4$ & $4 \pm 1$ \\
\hline \multirow[t]{2}{*}{ room B } & case 3a & 400 & $35 \pm 2$ & $12 \pm 6$ \\
\hline & case $3 b$ & 400 & $36 \pm 2$ & $21 \pm 8$ \\
\hline
\end{tabular}

Fig. 7 for case $1 \mathrm{~b}$ and $D_{\mathrm{CP}}=800 \mathrm{~ns}$. The theoretical quadratic decrease of the spectral interference profile (Section III-B4) is also included (grey solid line), where the factor $\left\langle\left|y_{\text {Four }, m}(\omega, 0)\right|^{2}\right\rangle_{m, \omega}$ is based on the analytical method. The agreement between the samples-based and the APDP-based method is excellent: for all cases for room A and $D_{\mathrm{CP}}=400 / 800 \mathrm{~ns}$, the deviation of all interference power terms is maximum $0.3 \mathrm{~dB}$.

The agreement between the analytical and the samples-based method is good: for all cases for room $\mathrm{A}$ and $D_{\mathrm{CP}}=400 / 800 \mathrm{~ns}$, the deviation of $\left\langle\left|y_{\text {corr }, m}(\omega)\right|^{2}\right\rangle_{m, \omega}$ is maximum $1.9 \mathrm{~dB}$ and the deviation of $\left\langle\left|y_{\text {Four }}\left(\omega, i^{\prime}-i\right)\right|^{2}\right\rangle_{m, \omega}$ for $0 \leq\left|i^{\prime}-i\right| \leq 19$ is maximum $1.3 \mathrm{~dB}$ (Fig. 7).

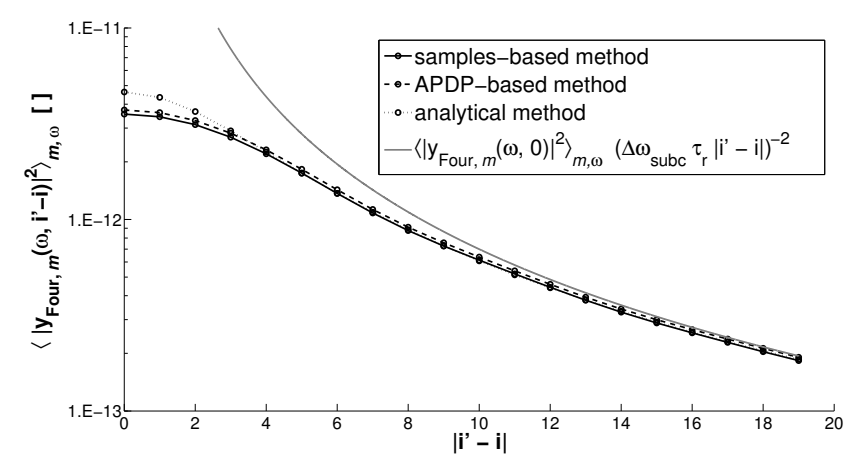

Fig. 7. The interference power $\left\langle\left|y_{\text {Four }, m}\left(\omega, i^{\prime}-i\right)\right|^{2}\right\rangle_{m, \omega}$ is experimentally determined for $0 \leq\left|i^{\prime}-i\right| \leq 19$ based on the samplesbased, APDP-based and analytical method. An excellent agreement is found. 


\section{V. $F_{\text {delay }}$ AND $L_{\text {delay }}$ FOR IEEE 802.11 IN LARGE CONFERENCE ROOMS}

$F_{\text {delay }}$ is determined for rooms $\mathrm{A}$ and B (Table II) using the analytical method: (21), where $\tau_{\mathrm{r}}$ and $I_{\text {diff }}$ are determined from the APDP (Table I). For room B, the values of $\tau_{\mathrm{r}}$ and $I_{\text {diff }}$ corresponding to $D_{\mathrm{CP}}=400 \mathrm{~ns}$ are also used for $D_{\mathrm{CP}}=800 \mathrm{~ns}$. As an additional validation, $F_{\text {delay }}$ in room A is also determined using the samplesbased method (based on (15)). Further, $F_{\text {delay }}$ is averaged over the considered frequency band, $2.65-2.85 \mathrm{GHz}$. The following IEEE 802.11 OFDM parameters are used: $N_{\text {sample }}=64, N_{\text {subc }}=52, D_{\mathrm{FFT}}=3.2 \mu \mathrm{s}, D_{\mathrm{CP}}=$ 400/800 ns and $P_{\mathrm{T}}=20 \mathrm{dBm}$ [18], [25].

For all cases in room A and $D_{\mathrm{CP}}=400 / 800 \mathrm{~ns}$, the deviation of $F_{\text {delay }}$ between the samples-based and the analytical method is maximum $1.1 \mathrm{~dB}$ (Table II), which is an excellent agreement. For $D_{\mathrm{CP}}=800 \mathrm{~ns}, F_{\text {delay }}$ is (averaged over all $\mathrm{Tx} / \mathrm{Rx}$ positions) $22.5 \mathrm{~dB}$ and $-56.9 \mathrm{~dB}$ in room $\mathrm{A}$ and $\mathrm{B}$, respectively. For $D_{\mathrm{CP}}=$ $400 \mathrm{~ns}, F_{\text {delay }}$ is $36.4 \mathrm{~dB}$ and $-7.9 \mathrm{~dB}$, respectively. As $F_{\text {delay }}$ is proportional to the transmit power, $F_{\text {delay }}$ is $10 \mathrm{~dB}$ higher for $P_{\mathrm{T}}=30 \mathrm{dBm}$. Compared to room $\mathrm{B}, F_{\text {delay }}$ in room $\mathrm{A}$ is about $44 \mathrm{~dB}$ and $80 \mathrm{~dB}$ higher for $D_{\mathrm{CP}}=400 \mathrm{~ns}$ and $800 \mathrm{~ns}$, respectively. This is due to the higher reverberation time in room A (averaged $122 \mathrm{~ns}$ vs $35 \mathrm{~ns}$ in room B), mainly via the factor $\exp \left(-D_{\mathrm{CP}} / \tau_{\mathrm{r}}\right)$ in $(21)$.

\section{TABLE II}

THE EFFECTIVE NOISE FACTOR $\left(F_{\text {delay }}\right)$ IS EXPERIMENTALLY DETERMINED FOR $P_{\mathrm{T}}=20 \mathrm{dBm}$ USING THE (I) SAMPLES-BASED AND (II) ANALYTICAL METHOD. THE LOSS FACTOR $\left(L_{\text {delay }}\right)$ IS GIVEN FOR $P_{\mathrm{T}}=20-30 \mathrm{dBm}$.

\begin{tabular}{|c|c|c|c|c|c|}
\hline \multirow[t]{2}{*}{ room } & \multirow{2}{*}{$\begin{array}{c}\mathrm{Tx} / \mathrm{Rx} \\
\text { position }\end{array}$} & \multirow{2}{*}{$\begin{array}{c}D_{\mathrm{CP}} \\
{[\mathrm{ns}]}\end{array}$} & \multicolumn{2}{|c|}{$F_{\text {delay }}[\mathrm{dB}]$} & \multirow{2}{*}{$\begin{array}{c}L_{\text {delay }}[\mathrm{dB}] \\
\quad\left(\text { for } P_{\mathrm{T}}=\right. \\
20-30 \mathrm{dBm})\end{array}$} \\
\hline & & & (i) & (ii) & \\
\hline \multirow[t]{8}{*}{$\mathrm{A}$} & \multirow[t]{2}{*}{ case $1 \mathrm{a}$} & 400 & 36.1 & 36.0 & $21.1-31.1$ \\
\hline & & 800 & 22.2 & 23.1 & $8.0-17.3$ \\
\hline & \multirow[t]{2}{*}{ case $1 b$} & 400 & 35.0 & 34.6 & $20.0-30.0$ \\
\hline & & 800 & 21.6 & 20.9 & $7.5-16.7$ \\
\hline & \multirow{2}{*}{ case $2 \mathrm{a}$} & 400 & 37.0 & 36.9 & $22.0-32.0$ \\
\hline & & 800 & 23.9 & 23.1 & $9.4-19.0$ \\
\hline & \multirow[t]{2}{*}{ case $2 b$} & 400 & 37.4 & 36.3 & $22.4-32.4$ \\
\hline & & 800 & 22.4 & 22.3 & $8.1-17.5$ \\
\hline \multirow[t]{4}{*}{ B } & \multirow[t]{2}{*}{ case $3 a$} & 400 & - & -10.0 & $0.0-0.1$ \\
\hline & & 800 & - & -59.6 & $0.0-0.0$ \\
\hline & \multirow[t]{2}{*}{ case $3 b$} & 400 & - & $\begin{array}{l}-5.8 \\
\end{array}$ & $0.0-0.4$ \\
\hline & & 800 & - & -54.1 & $0.0-0.0$ \\
\hline
\end{tabular}

The corresponding loss factor, $L_{\text {delay }}$, is determined based on (12) for $P_{\mathrm{T}}=20 / 30 \mathrm{dBm}$ and $F[\mathrm{~dB}]+$ $L_{\text {impl }}[\mathrm{dB}]=15 \mathrm{~dB}$ (Table II). For room A, the $F_{\text {delay }}$ values from the samples-based method are used. As in room B, $F_{\text {delay }}$ is much lower than $F \times L_{\text {impl }}, L_{\text {delay }}$ is about $0 \mathrm{~dB}$. In room $\mathrm{A}$ and for $P_{\mathrm{T}}=20 \mathrm{dBm}, L_{\text {delay }}$ is (averaged) $21.4 \mathrm{~dB}$ and $8.3 \mathrm{~dB}$ for $D_{\mathrm{CP}}=400 \mathrm{~ns}$ and $800 \mathrm{~ns}$, respectively. For $P_{\mathrm{T}}=30 \mathrm{dBm}, L_{\text {delay }}$ is even about $10 \mathrm{~dB}$ higher (up to $19 \mathrm{~dB}$ for $D_{\mathrm{CP}}=800 \mathrm{~ns}$ ). As these loss values are to be considered as a lower limit for realistic systems, the multipath noise causes a severe performance degradation in room A.

As $F_{\text {delay }}$ is strongly dependent on $D_{\mathrm{CP}}$ (Table II), a possible way-out to decrease $L_{\text {delay }}$ is to include a long CP option in the physical standard. In [12], a variable guard interval algorithm has already been presented for dynamic multipath channels. Based on (21), when switching $D_{\mathrm{CP}}$ from $800 \mathrm{~ns}$ to $1600 \mathrm{~ns}, L_{\text {delay }}$ in room A would be reduced from (averaged) $8 / 18 \mathrm{~dB}$ for $P_{\mathrm{T}}=20 / 30 \mathrm{~dB}$, resp., to a zero loss. Due to the larger overhead, the physical data rate would decrease by $17 \%$, but this would be largely compensated by the strong reduction of $L_{\text {delay }}$. To keep the data rate unchanged, $D_{\mathrm{FFT}}$ should increase proportionally to $D_{\mathrm{CP}}$. However, this implies a higher FFT processor size and a lower resistance against the Doppler effect [3].

Another strategy to mitigate the multipath noise is using a directive transmit antenna, properly oriented in the room, in order to reduce the multipath component. A related technique is ICI/ISI-aware beamforming [26]. Another technique is SINR-based antenna selection. The noise factor $F_{\text {delay,pack, } m}$ is expected to be uncorrelated between 2 antennas with a separation of the order of the wavelength, as it is based on the diffuse channel component. Hence, an additional gain is obtained by selecting the antenna with the highest SINR. Further, channel equalization techniques with ISI/ICI cancellation [5], [27] can also reduce the multipath noise. Finally, another strategy is more robust channel coding [5].

\section{CONCLUSIONS}

In this work, the performance loss due to multipath noise has been investigated for narrowband OFDM systems. We have found that the multipath noise, characterized by a packet-dependent noise factor $F_{\text {delay,pack, } m \text {, is }}$ described by an effective (packet-independent) AWGN with a noise factor $F_{\text {delay }}$, being the average of $F_{\text {delay,pack, } m}$ over all OFDM packets $m$. This concept has been shown theoretically for a sufficiently low outage 
probability $p_{\text {out }}$. It has also been validated with excellent agreement for realistic values of $p_{\text {out }}$ (i.e., $<50 \%$ ) based on virtual SIMO measurements.

Based on the theory of room electromagnetics, a closed-form analytical expression for $F_{\text {delay }}$ as a function of OFDM parameters and the reverberation parameters has been developed. This has been validated with excellent agreement based on the virtual SIMO measurements. This analysis shows that the reverberation time is an important channel property with respect to the performance degradation due to multipath noise. In addition, we found that the frequency width of the spectral interference power (due to the multipath noise) is directly related to the inverse of the reverberation time.

For IEEE 802.11, an $800 \mathrm{~ns}$ CP length and a $20 \mathrm{dBm}$ transmit power, we found that (averaged over all $\mathrm{Tx} / \mathrm{Rx}$ positions) $F_{\text {delay }}=22.5 \mathrm{~dB}$ and $-56.9 \mathrm{~dB}$ in room $\mathrm{A}$ and $\mathrm{B}$, respectively. This results into a respective performance loss $L_{\text {delay }}$ of about $8.3 \mathrm{~dB}$ and $0 \mathrm{~dB}$. For a $30 \mathrm{dBm}$ transmit power, $L_{\text {delay }}$ is even about $10 \mathrm{~dB}$ higher in room A. $F_{\text {delay }}$ is strikingly higher in room A, due to the higher reverberation time in room A compared to room B, i.e., (averaged) $122 \mathrm{~ns}$ vs $35 \mathrm{~ns}$.

\section{APPENDIX A}

\section{INTERFERENCE COEFFICIENTS $y_{\text {corr }, m}(\omega)$ AND}

$$
y_{\mathrm{Four}, m}\left(\omega, i^{\prime}-i\right)
$$

$y_{\text {corr }, m}(\omega)$ and $y_{\text {Four }, m}\left(\omega, i^{\prime}-i\right)$ are determined as the (continuous) Fourier transform of the channel impulse response, $c_{m}(\tau)$, multiplied by weighting functions $f_{\text {corr }}\left(\tau-\tau_{0}\right)$ and $f_{\mathrm{Four}, i^{\prime}-i}\left(\tau-\tau_{0}\right)$, resp.:

$$
\begin{aligned}
& y_{\text {corr }, m}(\omega)=\int_{0}^{\infty} \exp (-j \omega \tau) f_{\text {corr }}\left(\tau-\tau_{0}\right) c_{m}(\tau) \mathrm{d} \tau \\
& y_{\text {Four }, m}\left(\omega, i^{\prime}-i\right)= \\
& \int_{0}^{\infty} \exp (-j \omega \tau) f_{\mathrm{Four}, i^{\prime}-i}\left(\tau-\tau_{0}\right) c_{m}(\tau) \mathrm{d} \tau,
\end{aligned}
$$

where $\tau_{0}=\tau_{\min }+D_{\mathrm{CP}}+D_{\mathrm{FFT}}+D_{\mathrm{FFT}} N_{\text {sample }}^{-1} \cdot f_{\text {corr }}(\tau)$ and $f_{\mathrm{Four}, i^{\prime}-i}(\tau)$ are determined as in Tables III and IV. The function $f_{0, i^{\prime}-i}(\tau)$ is defined for $0<\tau<D_{\mathrm{FFT}}$ by

$$
f_{0, i^{\prime}-i}(\tau)=\frac{j}{2 \pi\left(i^{\prime}-i\right)}\left(\exp \left(-j\left(i^{\prime}-i\right) \Delta \omega_{\mathrm{subc}} \tau\right)-1\right) .
$$

\section{REFERENCES}

[1] A. Molisch, Wireless communications, 2nd ed. John Wiley \& Sons Ltd., 2011.
TABLE III

THE WEIGHTING FUNCTION $f_{\text {corr }}(\tau)$

\begin{tabular}{|c|c|}
\hline \multicolumn{2}{|c|}{$f_{\text {corr }}(\tau)=$} \\
\hline \hline$\tau<-D_{\mathrm{FFT}}$ & 0 \\
\hline$-D_{\mathrm{FFT}}<\tau<0$ & $1 /\left(2 N_{\text {sample }}\right)$ \\
\hline $0<\tau<D_{\mathrm{CP}}$ & 0 \\
\hline$D_{\mathrm{CP}}<\tau<D_{\mathrm{CP}}+D_{\mathrm{FFT}}$ & $-1 /\left(2 N_{\text {sample }}\right)$ \\
\hline$D_{\mathrm{CP}}+D_{\mathrm{FFT}}<\tau$ & 0 \\
\hline
\end{tabular}

TABLE IV

THE WEIGHTING FUNCTION $f_{\mathrm{Four}, i^{\prime}-i}(\tau)$

\begin{tabular}{|c|c|}
\hline \multicolumn{2}{|c|}{$f_{\mathrm{Four}, i^{\prime}-i}(\tau)=$} \\
\hline \hline$\tau<-D_{\mathrm{FFT}}$ & 0 \\
\hline$-D_{\mathrm{FFT}}<\tau<0$ & $\tau / D_{\mathrm{FFT}}+1\left(i^{\prime}=i\right)$ \\
& $f_{0, i^{\prime}-i}\left(\tau+D_{\mathrm{FFT}}\right)\left(i^{\prime} \neq i\right)$ \\
\hline $0<\tau<D_{\mathrm{CP}}$ & $1\left(i^{\prime}=i\right)$ \\
& $0\left(i^{\prime} \neq i\right)$ \\
\hline$D_{\mathrm{CP}}<\tau<D_{\mathrm{CP}}+D_{\mathrm{FFT}}$ & $\left(D_{\mathrm{CP}}-\tau\right) / D_{\mathrm{FFT}}+1\left(i^{\prime}=i\right)$ \\
& $-f_{0, i^{\prime}-i}\left(\tau-D_{\mathrm{CP}}\right)\left(i^{\prime} \neq i\right)$ \\
\hline$D_{\mathrm{CP}}+D_{\mathrm{FFT}}<\tau$ & 0 \\
\hline
\end{tabular}

[2] K.-W. Yip, T.-S. Ng, and Y.-C. Wu, "Impacts of multipath fading on the timing synchronization of IEEE 802.11a wireless LANs," in Communications, 2002. ICC 2002. IEEE International Conference on, New York City, NY, Apr. 2002.

[3] H. Steendam and M. Moeneclaey, "Analysis and optimization of the performance of OFDM on frequency-selective timeselective fading channels," IEEE Transactions on Communications, vol. 47, no. 12, pp. 1811-19, 1999.

[4] P. Bello, "Characterization of randomly time-variant linear channels," Communications Systems, IEEE Transactions on, vol. 11, no. 4, pp. 360 - 393, 1963.

[5] E. Viterbo and K. Fazel, "How to combat long echoes in OFDM transmission schemes: sub-channel equalization or more powerful channel coding," in Global Telecommunications Conference, 1995. GLOBECOM '95., IEEE, Singapore, Nov. 1995.

[6] J. Seoane, S. Wilson, and S. Gelfand, "Analysis of intertone and interblock interference in OFDM when the length of the cyclic prefix is shorter than the length of the impulse response of the channel," in Global Telecommunications Conference, 1997. GLOBECOM '97., IEEE, vol. 1, Phoenix, AZ, Nov. 1997, pp. $32-36$.

[7] V. D. Nguyen and H.-P. Kuchenbecker, "Intercarrier and intersymbol interference analysis of OFDM systems on timeinvariant channels," in Personal, Indoor and Mobile Radio Communications, 2002. The 13th IEEE International Symposium on, vol. 4, Lisboa, Portugal, Sep. 2002, pp. 1482 - 1487.

[8] G. Pantos, A. Kanatas, and P. Constantinou, "Performance evaluation of OFDM transmission over a challenging urban propagation environment," Broadcasting, IEEE Transactions on, vol. 49 , no. 1 , pp. 87 - 96, 2003. 
[9] V. D. Nguyen and H.-P. Kuchenbecker, "Intercarrier and intersymbol interference analysis of OFDM systems on timevarying channels," in Signal Processing Advances in Wireless Communications, 2003. SPAWC 2003. 4th IEEE Workshop on, Rome, Italy, Jun. 2003, pp. $140-144$.

[10] H. Steendam, "Parameter optimization for OFDM systems in doubly-selective fading channels with line-of-sight components," IEEE Transactions on Wireless Communications, vol. 6, no. 5, pp. 1626-30, 2007.

[11] W. Henkel, G. Taubock, P. Odling, P. Borjesson, and N. Petersson, "The cyclic prefix of OFDM/DMT - an analysis," in Broadband Communications, 2002. Access, Transmission, Networking. 2002 International Zurich Seminar on, Zurich, SW, Feb. 2002, pp. 22-1 - 22-3.

[12] S. S. Das, E. D. Carvalho, and R. Prasad, "Variable guard interval orthogonal frequency division multiplexing in dynamic channel condition," in Personal, Indoor and Mobile Radio Communications, 2006 IEEE 17th International Symposium on, Helsinki, Finland, Sep. 2006, pp. 1 - 5.

[13] F. Heereman et al., "Performance loss due to multipath propagation for IEEE 802.11 systems," in 2013 7th European Conference on Antennas and Propagation, EuCAP 2013, Göteborg, Sweden, Apr. 2013

[14] J. Montojo and L. Milstein, "Effects of imperfections on the performance of OFDM systems," Communications, IEEE Transactions on, vol. 57, no. 7, pp. 2060 - 70, 2009.

[15] V. Kotzsch, W. Rave, and G. Fettweis, "ISI analysis in network MIMO OFDM systems with insufficient cyclic prefix length," in Wireless Communication Systems (ISWCS), 2010 7th International Symposium on, York, UK, Sep. 2010, pp. 189 - 193.

[16] J. Andersen, J. Nielsen, G. Pedersen, G. Bauch, and M. Herdin, "Room electromagnetics," IEEE Antennas and Propagation Magazine, vol. 49, no. 2, pp. 27-33, 2007.

[17] F. Quitin, C. Oestges, F. Bellens, S. Van Roy, F. Horlin, and P. De Doncker, "Model parametrization and validation for specular-diffuse clustered channel models," IEEE Transactions on Antennes and Propagation, vol. 60, no. 8, pp. 4019 - 22, 2012.

[18] Part 11: Wireless LAN Medium Access Control (MAC) and Physical Layer (PHY) specifications High-speed Physical Layer in the $5 \mathrm{GHz}$ Band, IEEE Std., June 2003.

[19] A. Bamba et al., "Experimental assessment of specific absorption rate using room electromagnetics," Electromagnetic Compatibility, IEEE Transactions on, vol. 54, no. 4, pp. 747-57, 2012.

[20] Y. S. Cho, J. Kim, W. Y. Yang, and C. G. Kang, MIMO-OFDM wireless communications with MATLAB. John Wiley \& Sons, 2010.

[21] M. Zargari et al., "A single-chip dual-band tri-mode CMOS transceiver for IEEE $802.11 \mathrm{a} / \mathrm{b} / \mathrm{g}$ Wireless LAN," Solid-State Circuits, IEEE Journal of, vol. 39, no. 12, pp. 2239 - 49, 2004.

[22] M. Speth, S. A. Fechtel, G. Fock, and H. Meyr, "Optimum receiver design for wireless broad-band systems using OFDM Part I," IEEE Transactions on Communications, vol. 47, no. 11, pp. 1668 - 77, 1999.

[23] "Agilent fundamentals of RF and microwave noise figure measurements," Agilent Technologies, Tech. Rep., 2010.

[24] E. Tanghe, W. Joseph, J. De Bruyne, L. Verloock, and L. Martens, "The industrial indoor channel: statistical analysis of the power delay profile," International Journal of Electronics and Communications, vol. 64, no. 9, pp. 806-812, 2010.
[25] IEEE Std 802.11n ${ }^{T M}-2009$ amendment 5 to part 11: Wireless LAN Medium Access Control (MAC) and Physical Layer (PHY) specifications: enhancements for higher throughput, IEEE Std., Oct. 2009.

[26] X. Sun, Q. Wang, L. Cimini, L. Greenstein, and D. Chan, "ICI/ISI-aware beamforming for MIMO-OFDM wireless systems," IEEE Transactions on Wireless Communications, vol. 11, no. 1, pp. 378-385, 2012.

[27] J. Lee, T. Ohtsuki, and M. Nakagawa, "Performance of turbo equalized double window cancellation and combining in large delay spread channels," in Personal, Indoor and Mobile Radio Communications, 2009 IEEE 20th International Symposium on, Tokyo, JP, Sep. 2009, pp. $226-230$. 